\title{
Simple Measurement of IgA Predicts Immunity and Mortality in Ataxia-Telangiectasia
}

\author{
Stefan Zielen ${ }^{1} \cdot$ Ruth Pia Duecker ${ }^{1} \cdot$ Sandra Woelke $^{1} \cdot$ Helena Donath $^{1}$. Sharhzad Bakhtiar ${ }^{2}$. Aileen Buecker ${ }^{1}$. \\ Hermann Kreyenberg ${ }^{2}$. Sabine Huenecke ${ }^{2}$ - Peter Bader ${ }^{2}$ - Nizar Mahlaoui ${ }^{3}$. Stephan Ehl ${ }^{4}$. Sabine M. El-Helou ${ }^{4,5,6}$. \\ Barbara Pietrucha ${ }^{7}$. Alessandro Plebani ${ }^{8} \cdot$ Michiel van der Flier ${ }^{9} \cdot$ Koen van Aerde ${ }^{10} \cdot$ Sara S. Kilic $^{11}$. \\ Shereen M. Reda ${ }^{12}$. Larysa Kostyuchenko ${ }^{13}$. Elizabeth McDermott ${ }^{14} \cdot$ Nermeen Galal $^{15}$. Claudio Pignata ${ }^{16}$. \\ Juan Luis Santos Pérez ${ }^{17} \cdot$ Hans-Juergen Laws ${ }^{18} \cdot$ Tim Niehues $^{19} \cdot$ Necil Kutukculer $^{20} \cdot$ Markus G. Seidel $^{21}$. \\ Laura Marques $^{22}$. Peter Ciznar ${ }^{23}$. John David M. Edgar ${ }^{24}$. Pere Soler-Palacín ${ }^{25} \cdot$ Horst von Bernuth $26,27,28$. \\ Renate Krueger ${ }^{26}$. Isabelle Meyts ${ }^{29}$. Ulrich Baumann ${ }^{30}$. Maria Kanariou ${ }^{31}$ • Bodo Grimbacher ${ }^{4,5,32}$. Fabian Hauck ${ }^{33}$. \\ Dagmar Graf $^{34}$ • Luis Ignacio Gonzalez Granado ${ }^{35}$. Seraina Prader ${ }^{36}$. Ismail Reisli ${ }^{37}$. Mary Slatter ${ }^{38}$. \\ Carlos Rodríguez-Gallego ${ }^{39}$. Peter D. Arkwright ${ }^{40}$. Claire Bethune ${ }^{41}$. Elena Deripapa ${ }^{42}$. Svetlana O. Sharapova ${ }^{43}$. \\ Kai Lehmberg ${ }^{44} \cdot$ E. Graham Davies ${ }^{45} \cdot$ Catharina Schuetz $^{46} \cdot$ Gerhard Kindle $^{4,47} \cdot$ Ralf Schubert $^{1}$
}

Received: 28 January 2021 / Accepted: 25 June 2021 / Published online: 3 September 2021

(c) The Author(s) 2021

\begin{abstract}
Patients with ataxia-telangiectasia (A-T) suffer from progressive cerebellar ataxia, immunodeficiency, respiratory failure, and cancer susceptibility. From a clinical point of view, A-T patients with IgA deficiency show more symptoms and may have a poorer prognosis. In this study, we analyzed mortality and immunity data of 659 A-T patients with regard to IgA deficiency collected from the European Society for Immunodeficiencies (ESID) registry and from 66 patients with classical A-T who attended at the Frankfurt Goethe-University between 2012 and 2018. We studied peripheral B- and T-cell subsets and T-cell repertoire of the Frankfurt cohort and survival rates of all A-T patients in the ESID registry. Patients with A-T have significant alterations in their lymphocyte phenotypes. All subsets (CD3, CD4, CD8, CD19, CD4/CD45RA, and CD8/ CD45RA) were significantly diminished compared to standard values. Patients with IgA deficiency $(n=35)$ had significantly lower lymphocyte counts compared to A-T patients without IgA deficiency $(n=31)$ due to a further decrease of naïve CD4 T-cells, central memory CD4 cells, and regulatory T-cells. Although both patient groups showed affected TCR- $\beta$ repertoires compared to controls, no differences could be detected between patients with and without IgA deficiency. Overall survival of patients with IgA deficiency was significantly diminished. For the first time, our data show that patients with IgA deficiency have significantly lower lymphocyte counts and subsets, which are accompanied with reduced survival, compared to A-T patients without IgA deficiency. IgA, a simple surrogate marker, is indicating the poorest prognosis for classical A-T patients. Both non-interventional clinical trials were registered at clinicaltrials.gov 2012 (Susceptibility to infections in ataxia-telangiectasia; NCT02345135) and 2017 (Susceptibility to Infections, tumor risk and liver disease in patients with ataxia-telangiectasia; NCT03357978)
\end{abstract}

Keywords Ataxia-telangiectasia $\cdot \operatorname{IgA}$ deficiency $\cdot$ Immunoglobulins $\cdot$ Immunodeficiency $\cdot$ Lymphopenia $\cdot$ Mortality

\section{Introduction}

Ruth Pia Duecker

RuthPia.Duecker@kgu.de

Extended author information available on the last page of the article
Ataxia-telangiectasia (A-T) is a devastating human autosomal recessive disorder characterized by cerebellar degeneration, conjunctival telangiectasia, immunodeficiency, genetic instability, and cancer predisposition [1, 2]. Recurrent infections and aspiration contribute to lung disease leading 
to bronchiectasis and pneumonias and often to respiratory failure [3]. In addition, A-T patients show endocrine abnormalities, such as insulin resistance, liver disease, and growth retardation [4-8]. The prevalence of patients with A-T in Europe is estimated to be 1 in 150,000. The life expectancy of patients with "classical" A-T is only between 15 and 25 years of age [9]. The major cause of death is progressive lung disease and malignancies such as lymphoma or acute leukemia $[3,9]$. To date, no curative therapy is available for A-T.

It is known that deficiencies in both humoral and cellular immunity exist in A-T [10,11]. Frequent findings include IgA and IgG-subclass deficiencies and impaired antibody response to a variety of bacterial and viral antigens $[12,13]$. Lymphopenia of B- and T-cell subsets with diminished cellular immunity have been detected in in vivo and in vitro analyses [10,11]. T-cell functional defects compromise T-cell activation and proliferation [12], abnormalities in the T-cell receptor (TCR) repertoire $[14,15]$, and defects in early TCR signaling events [16, 17]. These deficiencies have been described even in young A-T patients, and no deterioration of immune function has been detected in the older A-T patients [13, 18].

There is considerable clinical variation between patients with A-T, and it is becoming evident that the clinical phenotype of A-T is correlated to the presence of residual ATM kinase activity which protects the patient from the more severe "classical" disease course with early death around 20 years of age $[19,20]$. Apart from residual ATM kinase activity, possible other factors, such as modifying genes and environmental factors, may contribute to a milder course of disease in some phenotypes of A-T [2].

Disease progression of A-T is demonstrable at different organ levels which are neurological decline, progressive lung disease, and liver disease [8]. Disease progression in all organs may be caused by multiple factors of which inflammation and oxidative stress play a dominant role [21-24]. The underlying mechanisms of disease progression are based on lack of major ATM functions. The major ATM functions comprise (1) ATM-dependent DNA damage response and regulation of DNA repair, (2) regulation of cell signaling and apoptosis, (3) telomere maintenance, (4) ATM-dependent response to oxidative stress, (5) mitochondrial homeostasis, and last (6) an involvement in cellular protein turnover. Thus, ATM-negative cells (neuron, lung, and liver cells) are unable to counteract inflammation and oxidative stress [22, $23,25]$.

From the clinical perspective, even in classical patients without residual ATM activity, the clinical course is highly variable, A-T patients with IgA deficiency seem to show more symptoms of immunodeficiency including a higher rate of granulomas and may have a poorer prognosis [3, 26]. It was reported in earlier studies that A-T represents many immunological different conditions [9, 19]. Evidence for this includes the widely different clinical features and course of patients like the growing appreciation of the significance of raised levels of IgM (hyper IgM phenotype) [27, 28], the presence of IgG subclass deficiency [19], and in rare cases a concomitant severe combined T-cell defect with a very poor prognosis [29]. Recently, van Os et al. [30] reported that patients with the hyper IgM phenotype and patients with an $\mathrm{IgG}_{2}$ deficiency showed decreased survival compared to patients with normal $\mathrm{IgG}$, respectively. In addition, the same group found that classical A-T patients with the ATM c. $3576 \mathrm{G}>\mathrm{A}$ mutation had a milder clinical phenotype in terms of prolonged survival and lower susceptibility to the development of malignancies and respiratory disease [30].

The potential immunopathogenic mechanisms with reference to this clinical heterogeneity are often not clear but have resulted in a plethora of possible mechanisms in those patients with mild or severe clinical phenotype. This prompted us to analyze the clinical history and immunological data of patients with classical A-T with and without IgA deficiency who attended the Frankfurt Goethe-University Hospital and the mortality data of the European Society for Immunodeficiency (ESID) registry.

\section{Patients and Methods}

\section{Data Ascertainment}

The data were collected (1) from the ESID registry and (2) from two non-interventional clinical trials at the Department for Children and Adolescence, Goethe-University, Frankfurt.

(1) Data of 659 A-T patients on age, gender, immunoglobulin levels $\operatorname{IgA}, \mathrm{IgG}_{2}$, IgM, and lymphocyte counts, date of birth, and date of death (until 2014) were collected from the ESID registry and analyzed for mortality. To avoid that patients are analyzed twice, patients from the Frankfurt cohort were excluded from the ESID cohort. A-T Patients were divided following their $\operatorname{IgA}$ status as deficient $(\operatorname{IgA}<0.07 \mathrm{~g} / \mathrm{L})$ and no deficient $(\operatorname{Ig} A \geq 0.07 \mathrm{~g} / \mathrm{L})[3,14]$. The Ig level of the last data entry in the ESID registry was determined, and Kaplan-Meier analysis was used to calculate the survival function from their corresponding lifetime data. Survival analysis was also performed for patients with combined $\operatorname{IgG}_{2}(<0.3 \mathrm{~g} / \mathrm{L})$ and $\operatorname{IgA}$ deficiency and with combined lymphopenia $(<1,000$ cells $/ \mu \mathrm{L})$ and $\mathrm{IgA}$ deficiency and compared to patients with $\mathrm{IgG}_{2}$ deficiency and lymphopenia with no deficient $\operatorname{IgA}$, respectively [31, 32]. An $\operatorname{IgA}(0.07$ to $<0.3 \mathrm{~g} / \mathrm{L}, \leq 12$ years and $\geq 0.3$ to $<0.7 \mathrm{~g} / \mathrm{L},>12$ years $)$ and $\operatorname{IgG}_{2}(>0.3$ to $<0.9 \mathrm{~g} / \mathrm{L}) \mathrm{g} / \mathrm{L}$ value below the age-appropriate normal range was defined as partial [14]. 
(2) Both non-interventional clinical trials were registered at clinicaltrials.gov 2012 (Susceptibility to infections in ataxia-telangiectasia; NCT02345135) and 2017 (Susceptibility to Infections, tumor risk and liver disease in patients with ataxia-telangiectasia; NCT03357978). These studies included 66 patients with classical A-T, aged two to 39 years, with a clinically and/or genetically confirmed diagnosis of A-T. Patients with $\operatorname{Ig} \mathrm{A}$ deficiency $(n=35)$ were compared to A-T patients without deficient $\operatorname{IgA}(n=31)$, which composed of 24 patients with normal IgA and seven patients with partial IgA levels. The A-T patients were diagnosed based on clinical criteria and alpha-fetoprotein (AFP) values, according to recent ESID recommendations (AT Diagnostic guidelines, ESID https://esid.org/ Working-Parties/Clinical-Working-Party/Resources/ Diagnostic-criteria-for-PID2). Written informed consent from patients or caregivers was obtained from each subject. The study was conducted following the ethical principles of the Declaration of Helsinki, regulatory requirements, and the code of Good Clinical Practice. The study was approved by the responsible ethics committees in Frankfurt. Retrieved parameters included patient growth chart and clinical findings, as well as blood parameters such as blood count, lymphocyte subpopulation count, immunoglobulin levels in serum (IgA, IgG and IgG subclasses, IgM), and AFP. Of the 66 A-T patients from the Frankfurt cohort that are listed in the manuscript, 39 patients were recorded in the ESID registry (Fig. 1a).

\section{Classification into Classical and Variant A-T}

The data of the ESID registry are collected by pediatricians and pediatric immunologist, and most patients (>95\%) were entered in the registry before the age of 9 years. Taken this into account, it seems very unlikely that patients with variant A-T were included in the ESID registry. Nevertheless, since ATM kinase activity was not measured in most A-T cases of the ESID registry, we performed a sensitivity analysis of survival and excluded all patients who had their 1st visit after the age of 9 years and who were older than 37.5 years to minimize the presence of A-T variants (Fig. S3).

In keeping with this approach, our pediatric center in Frankfurt, who is caring for 66 classical A-T cases in Germany, analyzed ATM kinase activity in the lab of AM Taylor, Birmingham, UK. So far, we did not detect residual ATM kinase activity in any our 66 reported cases [7,33].

\section{Immunoglobulins and Lymphocytes}

For a deeper insight into the immune status and to look for differences in cellular immunity between A-T patients with
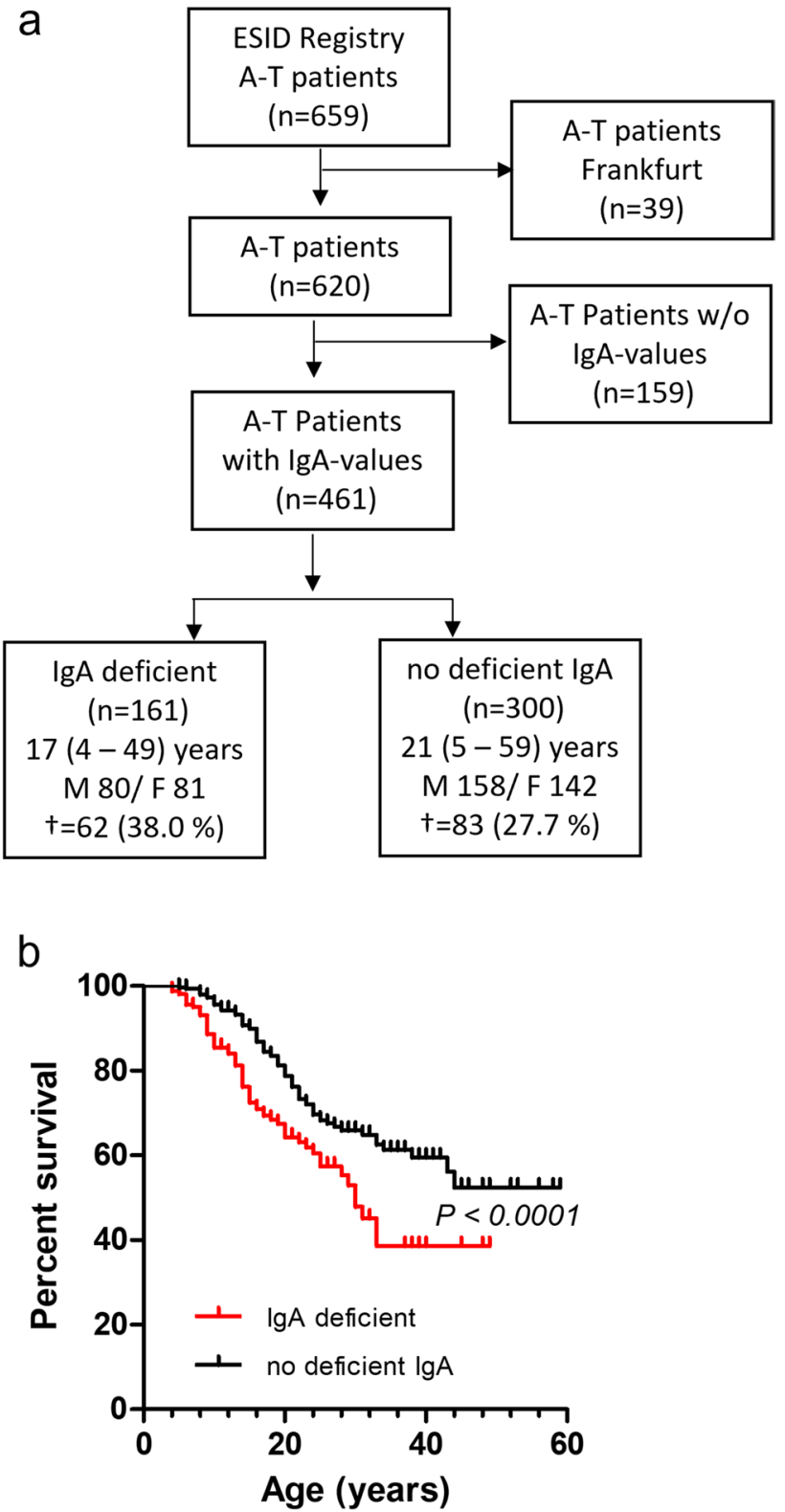

Fig. 1 IgA deficiency influences survival in A-T. a Flow chart of the analyzed patients from the ESID registry. b Survival of patients with deficient IgA and patients with no deficient $\operatorname{IgA} . \operatorname{IgA}<0.07 \mathrm{~g} / \mathrm{L}$ was defined as $\operatorname{IgA}$ deficient, and $\operatorname{Ig} \mathrm{A} \geq 0.07 \mathrm{~g} / \mathrm{L}$ was defined as no deficient $\operatorname{IgA}$ values below the age-appropriate normal range were defined as partial. ${ }^{\dagger}$ number of deceased patients

and without $\operatorname{Ig}$ A deficiency, we examined blood samples from the Frankfurt patient cohort. Serum IgG levels with subclasses, IgA and IgM, AFP as well as peripheral lymphocytes were routinely analyzed at the University Hospital.

Lymphocyte phenotyping was performed in a lyse-nowash procedure using $100 \mu \mathrm{L}$ of whole EDTA blood per tube. The absolute numbers of $\mathrm{CD}^{+}{ }^{+}$-cells, $\mathrm{CD} 3^{+} \mathrm{CD} 4^{+}$ helper T-cells, $\mathrm{CD}^{+}{ }^{+} \mathrm{CD} 8^{+}$cytotoxic T-cells, $\mathrm{CD}^{-}{ }^{-} \mathrm{CD} 56^{+}$ natural killer cells, and $\mathrm{CD} 19^{+} \mathrm{B}$-cells were determined 
with tetraCHROME combinational $\mathrm{mAb}$ reagents for CD45-FITC/CD4-PE/CD8-ECD/CD3-PC5 (B3821F4A/ SFCI12T4D11/SFCI21Thy2D3/UCHT1) and CD45FITC/CD56-PE/CD19-ECD/CD3-PC5 (B3821F4A/N901/ NKH-1/J3-119/UCHT1). Detection of naïve and memory T-cells was achieved introducing the following fluorochrome labelled antibodies: CD45RA-FITC (ALB11), CD45RO-PE (UCHL1), CD3-ECD (UCHT1), CD62L-PC5 (DREG56) CD4- (T4), or CD8-PC7 (T8). For the determination of regulatory T-cells (Tregs) as $\mathrm{CD} 4{ }^{+} \mathrm{CD} 25^{+} \mathrm{CD} 127^{\text {neg/dim }}$ cells, the antibodies CD3-FITC (UCHT1), CD127-PE (R34.34), CD4-ECD (T4), and CD25-PC7 (2A3) were used. All antibodies were conjugated with FITC, phycoerythrin (PE), phycoerythrin texas red (ECD), phycoerythrin-cyanine 5.1 (PC5), and phycoerythrin-cyanine 7 (PC7), respectively. All reagents are purchased from Beckman Coulter Immunotech (Marseilles, France) except CD25-PC7 (BD, Biosciences, Heidelberg, Germany). Measurements were performed on a Beckman Coulter FC500 five-color flow cytometer (Beckman Coulter, Krefeld, Germany). Absolute cell counts were calculated from the percentage values using a dual-platform approach. Flow-Set ${ }^{\mathrm{TM}}$ Fluorospheres served to set up the photo-multiplier tube values weekly. Stained Cyto-Comp ${ }^{\mathrm{TM}}$ Cells were applied to compensate the fluorescence overlap. The flow-cytometer optical alignment and the fluidic stability were tested daily using Flow-Check ${ }^{\mathrm{TM}}$ Fluorospheres. Immuno-Trol ${ }^{\mathrm{TM}}$ control cells were applied for verification.

\section{Immune Profiling by TCR-ß CDR3 Repertoire Analyses}

The composition of the T-cell receptor reflects the immune competence of the peripheral T-cell compartment. To figure out constraints of A-T patients compared to healthy individuals, we performed high-throughput sequencing of the TCR- $\beta$ CDR-3 regions using the survey level for library construction, which provides representative information about rearrangement frequency. TCR- $\beta$ CDR 3 repertoire analyses were performed from the Frankfurt patient cohort. Briefly, genomic DNA was extracted from peripheral blood samples using a column-based kit (QIAmp, Qiagen), and up to $2 \mu \mathrm{g}$ DNA were utilized for library generation. Rearranged TCR- $\beta$ gene segments were amplified by multiplex PCR, and resulting products were finally extended by barcode and adaptor sequences during a 2nd PCR (ImmunoSEQ hsTCRB Kit, Adaptive Biotechnologies). High throughput sequencing (HTS) was run on a MiSeq equipment using V3 reaction Kits (Illumina) with up to 25 barcoded samples in parallel (12 pM loading concentration, 5\% PhiX control). All samples were processed in duplicates, controls only once. Sequence data were analyzed with the online tool ImmunoSEQ Analyzer (Adaptive Biotechnologies) to acquire template counts (total and productive), productive clonality score on the base of Shannon entropy, and CDR3 length [34]. Calculated diversity index was obtained by dividing the number of unique rearrangements by the number of total templates [35].

\section{Statistics}

Basic descriptive statistics and statistical analyses were performed using GraphPad Prism 5.0 (GraphPad Software, San Diego, CA, USA). Values are presented as median (range) and were analyzed using the Student's t test, or for multiple comparisons, the one-way ANOVA with repeated measures was used. In case of not normally distributed data, the corresponding non-parametric testing was performed. The survival times of the patient groups were used to generate Kaplan-Meier survival curves which were compared using the Gehan-Breslow-Wilcoxon method, which gives more weight to deaths at early time points. Differences in survival between the groups were evaluated using the Cox proportional hazard model to calculate hazard ratios (HR) with 95\% CIs. $\mathrm{P}<0.05$ was considered as statistically significant.

\section{Results}

\section{Patient Data from the ESID Registry}

The ESID registry comprised 659 A-T patients of which 39 patients from the Frankfurt cohort were excluded (Fig. 1a). Of these 620 patients, 461 patients had data available for IgA with a complete dataset for age, gender, and lifetime. Of these in turn, 161 patients were IgA deficient, and 300 patients had no deficient IgA with normal $(n=141)$ or partial $(n=149)$ IgA levels (Fig. 1a, Table 1). Ten patients exhibited increased IgA values. Comparison of patients with and without IgA showed that beside IgA levels, none of the other immunoglobulins were different between the groups. It is important to note that median age was significantly lower in patients with IgA deficiency (Table 1).

Of the 461 patients who had data available for IgA, 171 patients also had data available for $\operatorname{IgG}_{2}, 458$ patients for $\operatorname{IgM}$, and 388 patients for total lymphocyte counts (Table S1). IgA deficiency was found in $34.9 \%$ and $\operatorname{IgG}_{2}$ deficiency in $29.2 \%$ of the patients. IgA levels were partial in $32.3 \%, \mathrm{IgG}_{2}$ levels in $25.2 \%$, IgM levels in $3.7 \%$, and lymphocyte counts in $47.7 \%$ of the patients. Increased IgAlevels were found in $2.2 \%, \mathrm{IgG}_{2}$ levels in $5.8 \%$, IgM levels in $17.2 \%$, and lymphocyte counts in $3.4 \%$ of the A-T patients.

\section{Frankfurt Patient's Characteristics}

From the Frankfurt cohort, 35/66 (53\%) patients, median 10 years, aged from 1 to 38 years, of whom 19 males and 16 
Table 1 A-T patients from the ESID-registry

\begin{tabular}{|c|c|c|c|c|}
\hline & All patients & $\begin{array}{l}\text { no deficient IgA } \\
(\operatorname{IgA} \geq 0.07 \mathrm{~g} / \mathrm{L})\end{array}$ & IgA deficient $(\operatorname{Ig} \mathrm{A}<0.07 \mathrm{~g} / \mathrm{L})$ & $\mathrm{P}$ value \\
\hline No. of patients (n) & 461 & 300 & 161 & - \\
\hline Age (years) & $19(4-59)$ & $21(5-59)$ & $17(4-49)$ & 0.0001 \\
\hline $\operatorname{Sex}(M / F)$ & $238 / 223$ & $158 / 142$ & $80 / 81$ & n.s \\
\hline $\operatorname{IgA}(\mathrm{g} / \mathrm{L})$ & $0.25(0.0-20.8)$ & $0.70(0.07-20.8)$ & $0.06(0.0-0.069)$ & 0.0001 \\
\hline $\operatorname{IgG}(\mathrm{g} / \mathrm{L})$ & $9.04(0.08-31.5)$ & $9.1(0.08-31.05)$ & $9.03(0.08-21.2)$ & n.s \\
\hline $\mathrm{IgG}_{2}(\mathrm{~g} / \mathrm{L})$ & $0.69(0.0-33.7)$ & $0.63(0.0-30.0)$ & $0.85(0.0-33.7)$ & n.s \\
\hline $\mathrm{IgG}_{4}(\mathrm{~g} / \mathrm{L})$ & n.d & n.d & n.d & \\
\hline $\operatorname{IgM}(\mathrm{g} / \mathrm{L})$ & $1.561(0.08-55.5)$ & $1.57(0.08-55.5)$ & $1.70(0.10-26.7)$ & n.s \\
\hline Lymphocytes (cells/ $\mu \mathrm{L})$ & $1560(120-17,330)$ & $1600(120-17,330)$ & $1495(140-12,190)$ & n.s \\
\hline$\alpha$-feto-protein (ng/mL) & $145(1.89-1190)$ & $158(1.89-1190)$ & $123(4.71-973)$ & n.s \\
\hline CRP & n.d & n.d & n.d & \\
\hline Granulomas & n.d & n.d & n.d & \\
\hline
\end{tabular}

* included patients with partial IgA-D $(n=149)$ females presented with IgA deficiency, 31 patients exhibited no deficient $\operatorname{IgA}$, median age 15 years ranging from 2 to 39 years, 16 males and 15 females. Of them 24 patients had normal and seven patients had partial IgA-levels (Table 2). Beside IgA, all other immunoglobulin and AFP levels were not different between the groups. Interestingly, A-T patients with IgA deficiency had a significant higher number of episodes with a significant elevation of CRP $>2 \mathrm{mg} / \mathrm{dL}$ and suffered more often from cutaneous granulomas and recurrent pneumonia (Table S3).

\section{Survival Analysis}

Of the $461 \mathrm{~A}-\mathrm{T}$ patients of the ESID registry with available IgA-values, 161 patients exhibited an IgA deficiency, whereas 300 showed normal $(n=141)$, partial $(n=149)$, or increased $(n=10)$ IgA levels. As shown in Fig. 1, A-T patients with deficient IgA died significantly earlier than patients with no deficient $\operatorname{IgA}(\mathrm{p}<0.0001)$. The corresponding hazard ratio (HR) for patients with IgA deficiency compared to those with $\mathrm{IgA}$-levels greater than $0.07 \mathrm{~g} / \mathrm{L}$ was 1.9 (1.34-2.77).

Fifty out of 171 A-T patients exhibited a deficient $\mathrm{IgG}_{2}$ (Fig. 2). This group of patients showed no difference in mortality rate compared to patients with no deficient $\mathrm{IgG}_{2}$ levels with a HR of $0.9(0.3-1.5)$. In contrast, A-T patients with both $\mathrm{IgG}_{2}$ deficiency and IgA deficiency showed a higher mortality than patients with $\mathrm{IgG}_{2}$ deficiency and no deficient IgA values (HR 2.9, 0.9-9.2).

Analysis of the ESID registry data revealed further that 185 patients out of 388 suffer from lymphopenia (Fig. 3). Patients from this group died at a younger age than patients
Table 2 A-T patients from the Frankfurt cohort

\begin{tabular}{|c|c|c|c|c|}
\hline & All patients & $\begin{array}{l}\text { no deficient } \operatorname{IgA} \\
(\operatorname{IgA} \geq 0.07 \mathrm{~g} / \mathrm{L})\end{array}$ & IgA deficient $(\operatorname{Ig} \mathrm{A}<0.07 \mathrm{~g} / \mathrm{L})$ & $\mathrm{P}$ value \\
\hline No. of patients (n) & 66 & 31 & 35 & - \\
\hline Age (years) & $12(1-39)$ & $15(2-39)$ & $10(1-38)$ & n.s \\
\hline $\operatorname{Sex}(M / F)$ & $35 / 31$ & $16 / 15$ & $19 / 16$ & - \\
\hline $\operatorname{IgA}(\mathrm{g} / \mathrm{L})$ & $0.06(0.002-2.25)$ & $11.0(0.3-2.25)$ & $0.05(0.002-0.06)$ & 0.0001 \\
\hline $\operatorname{IgG}(\mathrm{g} / \mathrm{L})$ & $8.70(0.66-21.5)$ & $8.34(3.96-21.5)$ & $9.01(0.66-20.6)$ & n.s \\
\hline $\mathrm{IgG}_{2}(\mathrm{~g} / \mathrm{L})$ & $0.69(0.11-6.98)$ & $0.64(0.12-2.76)$ & $0.82(0.11-6.98)$ & n.s \\
\hline $\mathrm{IgG}_{4}(\mathrm{~g} / \mathrm{L})$ & $0.02(0.00-0.42)$ & $0.03(0.00-0.42)$ & $0.02(0.00-0.23)$ & n.s \\
\hline $\operatorname{IgM}(\mathrm{g} / \mathrm{L})$ & $1.53(0.17-5.45)$ & $1.67(0.72-5.45)$ & $1.19(0.17-2.73)$ & n.s \\
\hline Lymphocytes (cells/ $\mu \mathrm{L}$ ) & $1335(180-3660)$ & $1608(595-3660)$ & $1142(180-2700)$ & 0.01 \\
\hline$\alpha$-feto-protein (ng/mL) & $278(28.7-1264)$ & $266(28.7-1264)$ & $332(49-1044)$ & n.s \\
\hline $\mathrm{CRP}^{\S}$ & 18 & 4 & 14 & 0.05 \\
\hline Granulomas & 8 & 1 & 7 & 0.058 \\
\hline
\end{tabular}

* included patients with partial $\operatorname{IgA}-\mathrm{D}(n=7)$, all of them aged above 12 years of age and an $\operatorname{IgA}$ level $>0.3 \mathrm{~g} / \mathrm{L}$. $\S$ number of episodes with a significant elevation of CRP $>2 \mathrm{mg} / \mathrm{dL}$ 
Fig. 2 Effect of IgA deficiency on survival of A-T patients with $\mathrm{IgG}_{2}$ deficiency. a Flow charts of the analyzed patient cohorts. b Survival of patients with deficient $\mathrm{IgG}_{2}$ and patients with no deficient $\mathrm{IgG}_{2}$. c Survival of patients with deficient $\mathrm{IgG}_{2}$ only and patients with deficient $\operatorname{IgG}_{2}$ and deficient $\operatorname{IgA}$. $\operatorname{IgA}<0.07 \mathrm{~g} / \mathrm{L}$, and $\mathrm{IgG}_{2}<0.3$ were defined as deficient. ${ }^{\dagger}$ number of deceased patients

Fig. 3 Effect of IgA deficiency on survival of A-T patients with lymphopenia. a Flow charts of the analyzed patient cohorts. b Survival of patients with lymphopenia and patients with normal lymphocytes. c Survival of patients with lymphopenia only and patients with lymphopenia and deficient $\operatorname{IgA}$. $\operatorname{Ig} \mathrm{A}<0.07 \mathrm{~g} / \mathrm{L}$ was defined as deficient. Lymphopenia was defined as $\leq 1,500$ cells $/ \mu \mathrm{L}$. ${ }^{\dagger}$ number of deceased patients
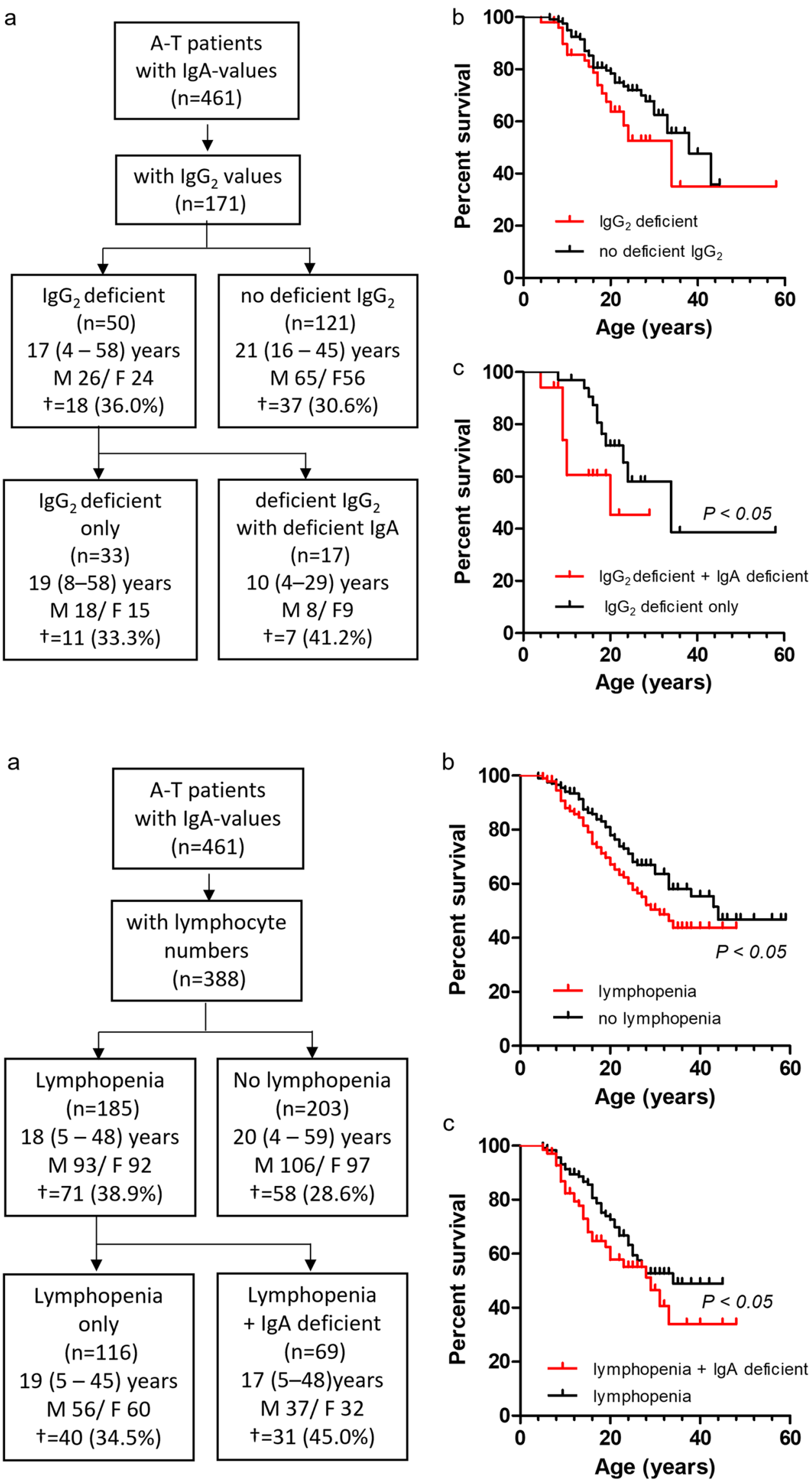
with normal lymphocyte counts with a HR of 1.5 (1.1-2.2). Death rate was found further increased when patients exhibit lymphopenia together with an IgA deficiency (HR $1.5(0.9-2.5))$.

\section{Ig-Replacement Therapy}

In the ESID registry data about therapeutic treatments were available from 298 patients. Treatments included Ig-replacement (204), antibiotics (61), and others (antidepressant (1), anti-reflux drug (1), cytostatic (1), growth hormones (1), $\mathrm{H} 2$ receptor blocker (1), steroid (2), vitamins (3), iron (1), neurological (1), immunostimulant (1), and immunosuppressant (1)) (Fig. S1). No differences could be detected in the percentage of Ig-replacement therapy between patients with IgA deficiency and patients with no deficient IgA.

\section{Cause of Death}

Data about the cause of death was available from 60 A-T patients with available IgA values in the ESID registry and the patients from the Frankfurt cohort (Fig. S2). Of these, 27 died from respiratory failure, 29 died from cancer, and 4 died for other reasons. While little more patients with no deficient IgA died from respiratory failure (respiratory failure 52.9\%; cancer $44.1 \%$ ), the group with IgA deficiency exhibited a slightly higher proportion of patients who died from cancer (respiratory failure $43.5 \%$; cancer $56.5 \%$ ).

\section{Decreased Lymphocyte Subpopulations in A-T Patients with IgA Deficiency}

Patients with A-T have significant alterations in their lymphocyte phenotypes [11] . Subsets of CD3, CD4, CD8, CD4/ CD45RA, and CD8/CD45RA cells were significantly diminished compared to age matched standard values. In A-T patients with IgA deficiency, total numbers of lymphocytes were significantly decreased ( 1148 cells $/ \mu \mathrm{L}, 180-2700)$ compared to patients with no deficient IgA (1592 cells/ $\mu \mathrm{L}, 595-3660, \mathrm{p}<0.01)$. This was evident particularly for CD3 T-cells (IgA-D: 613 cells/ $\mu \mathrm{L}, 251-1775$; noDef: 865 cells/ $\mu \mathrm{L}, 299-2599 ; \mathrm{p}<0.01$ ), for helper T-cells (IgA-D: 335 cells/ $\mu \mathrm{L}, 97-1459$; noDef: 505 cells/ $\mu \mathrm{L}, 162-1389$; $\mathrm{p}<0.01$ ), and for regulatory T-cells (IgA-D: 16 cells $/ \mu \mathrm{L}$, 1-33 noDef: 24 cells $/ \mu \mathrm{L}, 8-64 ; \mathrm{p}<0.05)$ but not for cytotoxic T-cells, B-cells, and NK-cells (Fig. 4).

Differences in CD4 T-cells were found in the naïve CD $4{ }^{+} \mathrm{CD} 45 \mathrm{RA}^{+} \mathrm{CD}^{2} 2 \mathrm{~L}^{+}(\mathrm{IgA}-\mathrm{D}, 19$ cells $/ \mu \mathrm{L}, 1-311$;
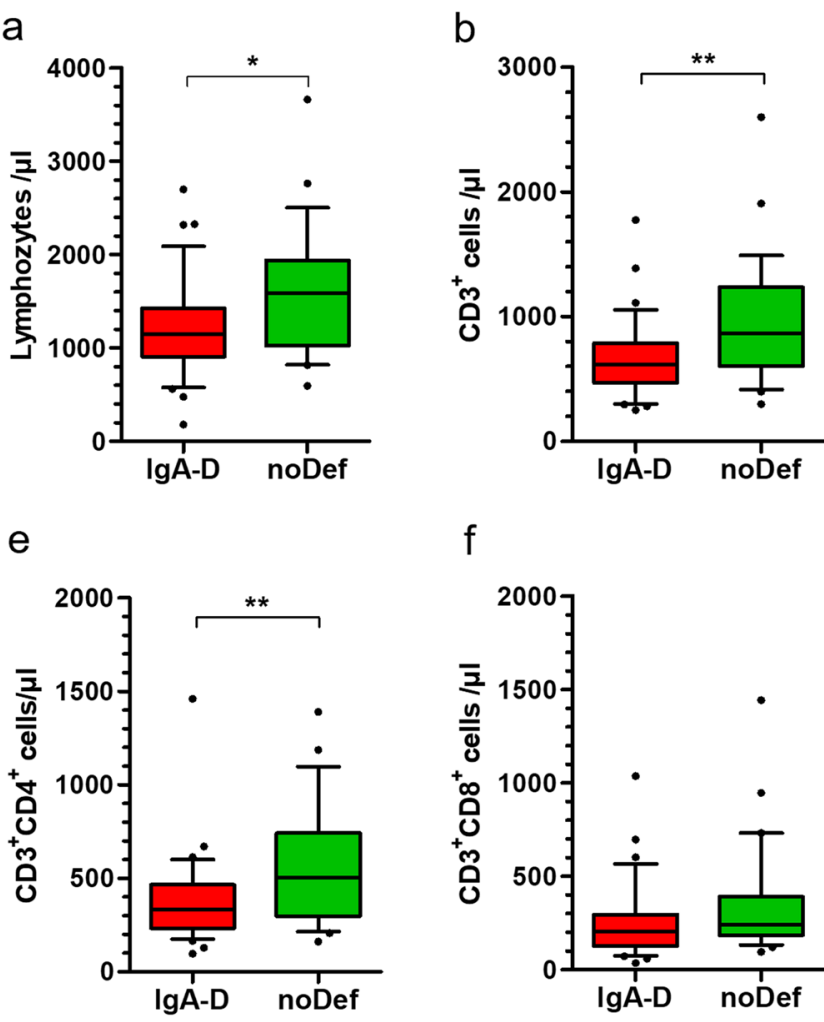

f

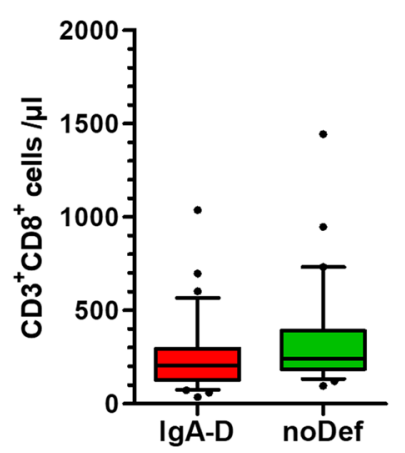

Fig. 4 Lymphocytes in A-T patients with deficient $\operatorname{IgA}$ (IgA-D) and no deficient $\operatorname{IgA}$ (noDef). Blood samples of A-T patients were analyzed for total numbers of a CD3 ${ }^{+}$T-cells, b CD19 ${ }^{+}$B-cells, c
C
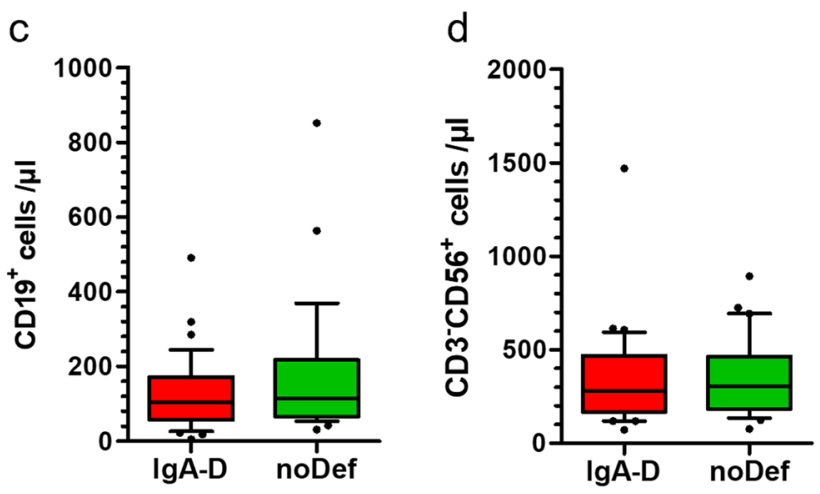

g

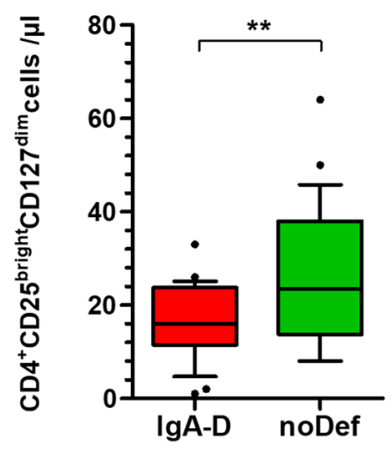

CD3-CD56 ${ }^{+}$NK-cells, d CD3 ${ }^{+} \mathrm{CD}^{+}$helper T-cells, e $\mathrm{CD}^{+}{ }^{+} \mathrm{CD} 8^{+}$ cytotoxic T-cells and $\mathbf{f} \mathrm{CD} 4^{+} \mathrm{CD} 25^{\text {bright }} \mathrm{CD} 127^{\mathrm{dim}}$ regulatory T-cells. IgA-D. $* \mathrm{p}<0.05, * * \mathrm{p}<0.01$ 
noDef, 48 cells $/ \mu \mathrm{L}, 6-540 ; \mathrm{p}<0.05)$ as well as in the central memory CD4 ${ }^{+} 45 \mathrm{RO}^{+} 62 \mathrm{~L}^{+}(\operatorname{IgA}-\mathrm{D}, 164$ cells $/ \mu \mathrm{L}$, 60-422; noDef, 274 cells/ $\mu \mathrm{L}, 59-1145 ; \mathrm{p}<0.01)$ T-cell subpopulation (Fig. 5).

\section{T-cell Receptor Rearrangements}

We evaluated the mean template numbers and range of $23,470$ (5514 to 55,205$), 18,626$ (4195 to 41,586$)$, and 21,507 (9332 to 32,357) for case, cohort, and control, respectively. Beneath that, we identified unique productive rearrangement numbers and range of 7211 (1253 to 13,687 ), 7249 (1394 to 25,601 ), and 12,802 (6374 to $18,151)$ in the same order as before. Both patient groups show affected TCR- $\beta$ repertoires characterized by the diminished portion of functional rearrangements and by tendency of clonal expansion (Fig. 6a-c).
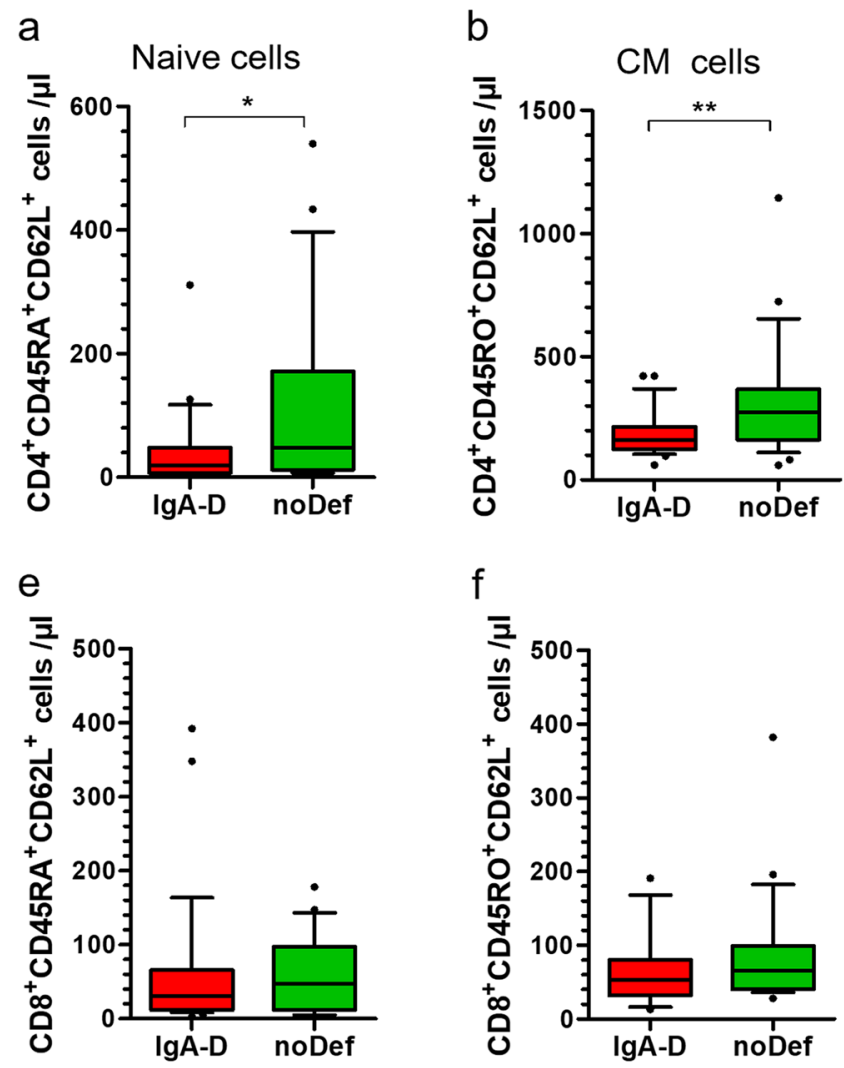

Fig. 5 T-cell subpopulations in A-T patients with deficient $\operatorname{IgA}(\operatorname{IgA}$ D) and no deficient IgA (noDef). Blood samples of A-T patients were analyzed for total numbers of a $\mathrm{CD} 4^{+} \mathrm{CD} 45 \mathrm{RA}^{+} \mathrm{CD} 62 \mathrm{~L}^{+}$ naïve T-cells, b $\mathrm{CD}^{+} \mathrm{CD}^{2} 5 \mathrm{RO}^{+} \mathrm{CD}_{2} \mathrm{~L}^{+}$central memory $(\mathrm{CM})$ T-cells c CD $4{ }^{+} \mathrm{CD} 45 \mathrm{RO}^{+} \mathrm{CD}_{2} \mathrm{~L}^{-}$effector memory (EM) T-cells, d

\section{Discussion}

At present, no curative therapy for A-T exists, but new treatment options like stem cell therapy, infusions of erythrocytedelivered dexamethasone and antisense oligonucleotide (ASO) are emerging $[2,33,36]$. Thus, markers of disease progression and long-term outcome are urgently needed to define patients with the poorest prognosis who might be considered first for such new treatments. The major interest of the present study is to investigate the clinical and immunological consequences of IgA deficiency in A-T and whether IgA is a possible marker to assess the prognosis of A-T patients. Therefore, we analyzed the mortality data of 659 A-T patients of the European Society for Immunodeficiency (ESID) registry as well as the clinical history and immunological data of patients with classical A-T with and without IgA deficiency of our Frankfurt patient cohort. Our study confirmed earlier findings that immunodeficiency is closely related to decreased survival in A-T [19, 27]. This is particularly evident for A-T patients with $\mathrm{IgG}_{2}$ and IgA deficiency. In contrast to the study of van Os et al. which
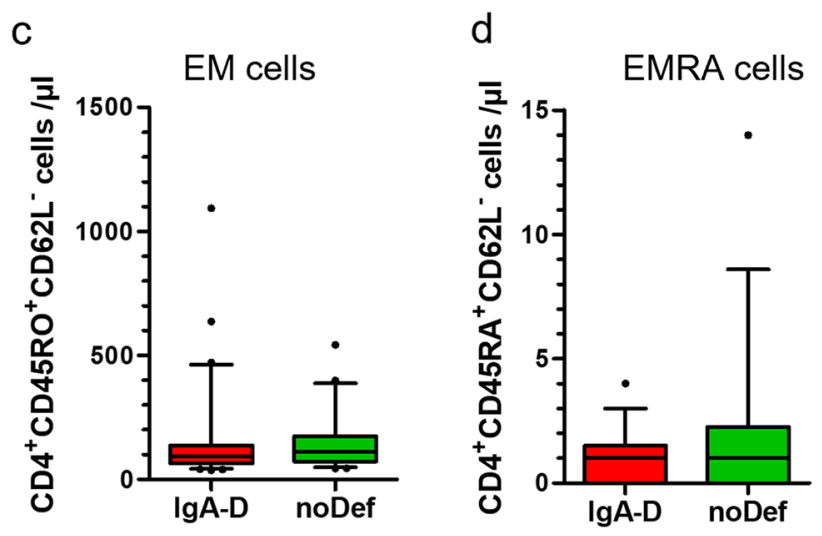

g
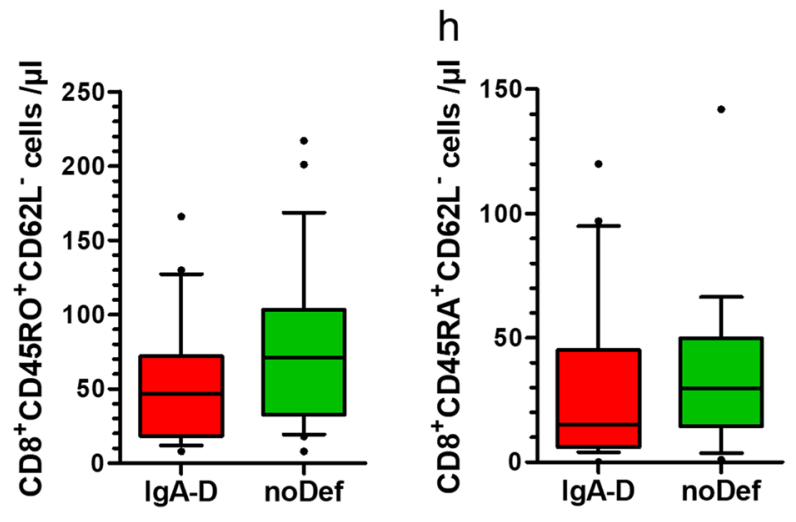

CD4 ${ }^{+}$CD45RA ${ }^{+}$CD62 $L^{-}$effector memory RA (EMRA) T-cells, e $\mathrm{CD}^{+} \mathrm{CD}^{2} 5 \mathrm{RA}^{+} \mathrm{CD} 2 \mathrm{~L}^{+}$naïve T-cells, f $\mathrm{CD}^{+} \mathrm{CD} 45 \mathrm{RO}^{+} \mathrm{CD} 62 \mathrm{~L}^{+}$ central memory $(\mathrm{CM}) \mathrm{T}$-cells g $\mathrm{CD}^{+} \mathrm{CD} 45 \mathrm{RO}^{+} \mathrm{CD}^{2} 2 \mathrm{~L}^{-}$effector memory (EM) T-cells, h $\mathrm{CD}^{+} \mathrm{CD} 45 \mathrm{RA}^{+} \mathrm{CD}^{2} 2 \mathrm{~L}^{-}$effector memory RA (EMRA) T-cells. $* \mathrm{p}<0.05, * * \mathrm{p}<0.01$ 
Fig. 6 T-cell rearrangement in A-T patients with deficient IgA (IgA-D), no deficient IgA (noDef) and controls. a CDR3 length distribution of the TCR- $\beta$ repertoire given as relative frequency (total $=1$ ) for control, noDef, and IgA-D samples. b Calculated diversity index of controls and both patient groups. c Productive clonality score of controls and both patient groups. The clonality score is derived from the Shannon entropy, which is calculated from the frequencies of all productive sequences divided by the logarithm of the total number of unique productive sequences. This normalized entropy value is then inverted ( 1 - normalized entropy) to produce the clonality metric. Entropy was calculated by summing the frequency of each clone times the log (base 2) of the same frequency over all productive reads in a sample

a

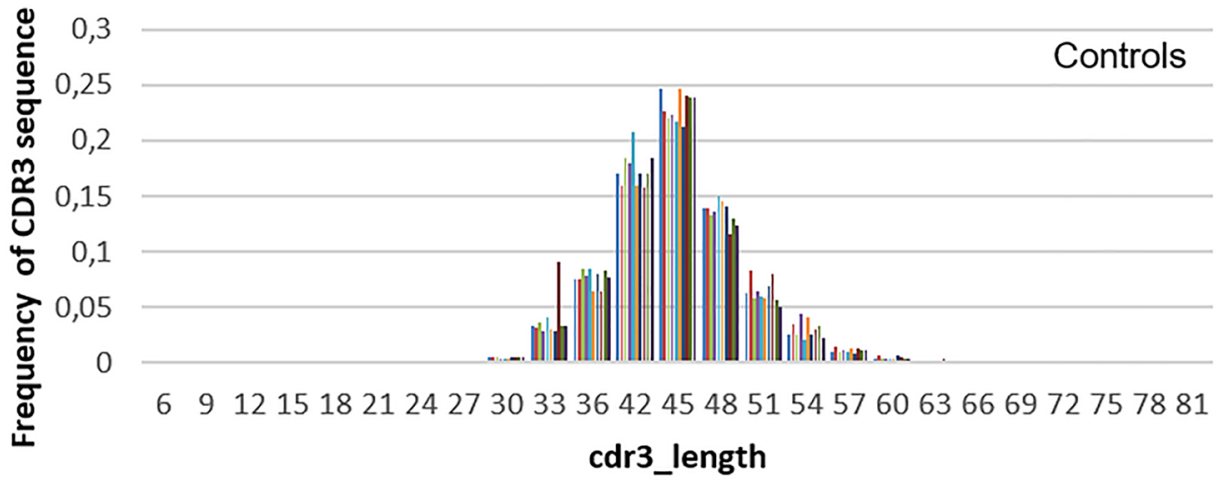

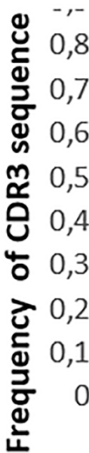
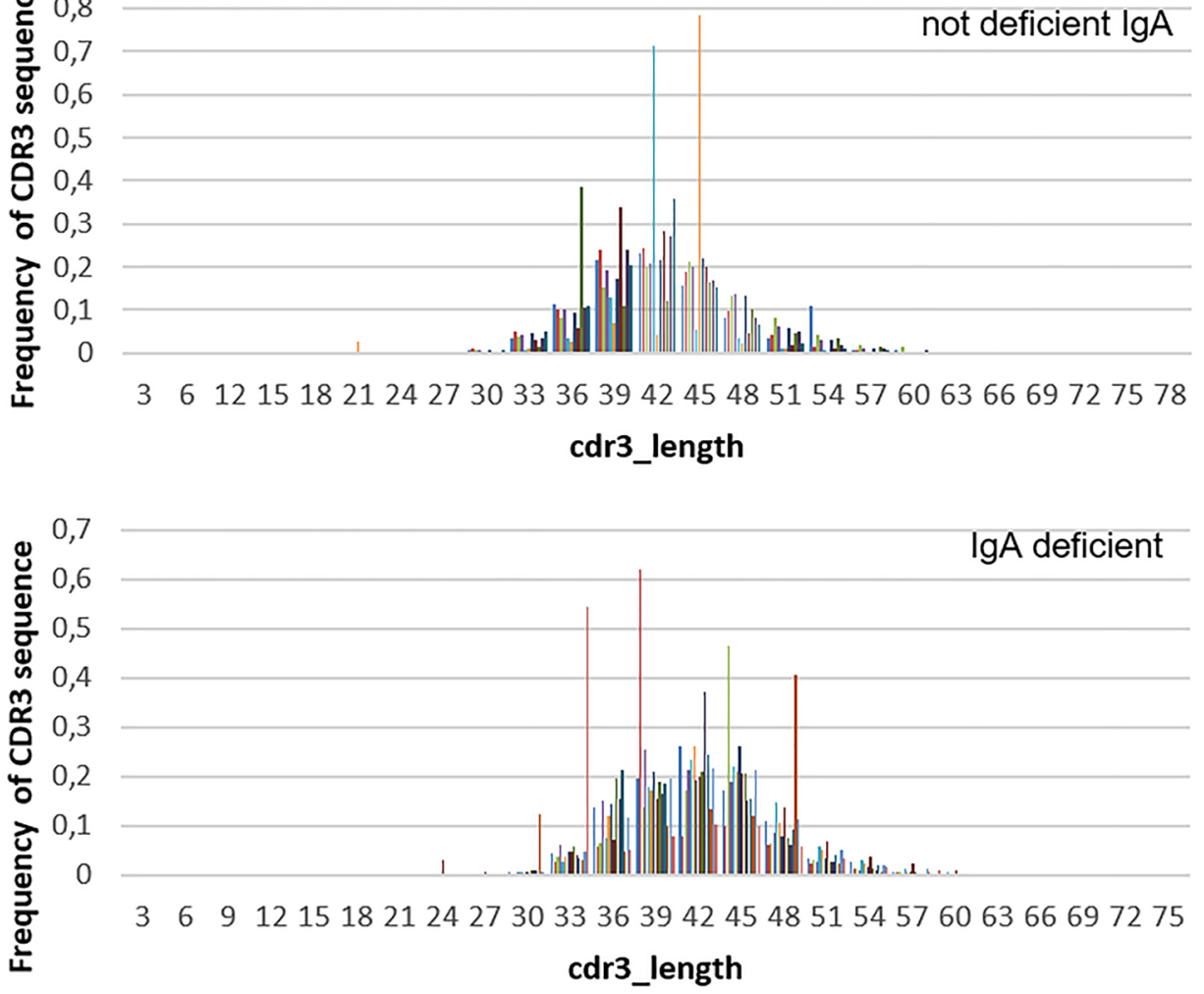

b

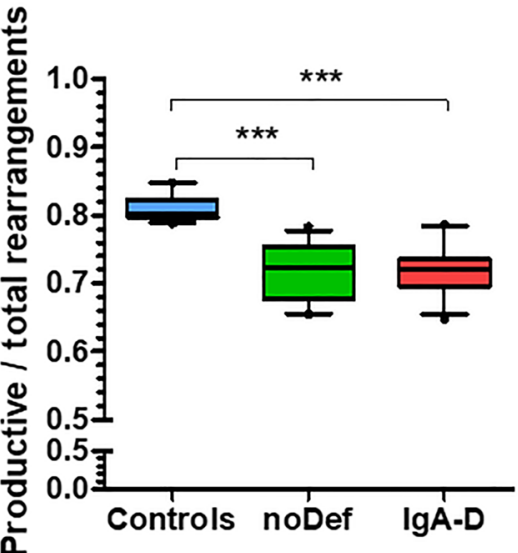

C

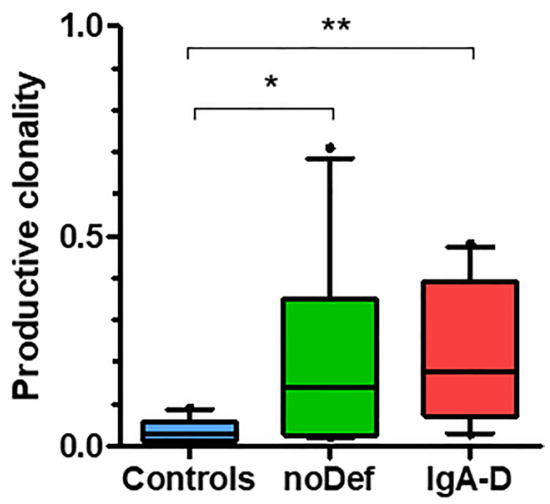


found similar survival for A-T patients with and without IgA deficiency, our data provide strong evidence for an influence of IgA deficiency on survival in A-T [19]. These contradictory results might be explained by the much larger cohort of 461 A-T patients analyzed in the present study. In contrast to Os et al., no differences in survival between A-T patients with and without $\mathrm{IgG}_{2}$ deficiency were seen. This finding could be based on the proportion of patients with concurrent IgA deficiency. Indeed, IgA deficiency significantly reduced survival of A-T patients with $\operatorname{IgG}_{2}$ deficiency and further reduced survival of patients with lymphopenia. The lack of difference in survival of patients with $\operatorname{IgA}$ and $\operatorname{IgG}_{2}$ deficiency in the Frankfurt cohort might be explained by the relatively low numbers. In addition, none of the patients in the Frankfurt cohort died on respiratory failure before the age of 20 years.

Abnormalities of immunoglobulin profiles and defective polysaccharide antibody synthesis are well known in A-T $[11,12,19,37,38]$. In our large cohort, $\operatorname{IgA}$ and $\operatorname{IgG}_{2}$ deficiencies were found in 34.9 and $29.2 \%$ of patients, whereas the hyper IgM phenotype was present in $17.2 \%$ of patients only. The pathogenesis of the hyper IgM phenotype, $\operatorname{IgA}$ and $\mathrm{IgG}_{2}$ deficiency is still unknown; however, a defective terminal differentiation of B-cells may be responsible. Recently, it was shown that inactivation of the DNA damage response pathway like in A-T cells leads to an impaired class switch recombination $[39,40]$.

While our data show that presence of $\operatorname{Ig} \mathrm{A}$ is associated with a better survival, the basic mechanisms involved are not clear. In general, $\operatorname{IgA}$ deficiency is often found in healthy blood donors with a defect in the differentiation of IgA cell-producing plasma B-cells but without any harm of such individuals [41]. The functions of $\operatorname{IgA}$ at the body surface are well known. IgA forms a barrier against pathogens by neutralizing bacterial products and impedes pathogens to penetrate the mucosal epithelium [42]. In addition, IgA is downregulating inflammatory cell responses via Fc $\alpha \mathrm{RI}$ and may act as an important non-inflammatory regulator of mucosal immunity [43]. The important role of IgA is supported by the fact that several bacteria have developed escape mechanisms by producing IgA 1 proteases or molecules that hamper interaction with IgA receptors [42]. Our finding of an elevated number of episodes with increased CRP in patients with IgA-deficiency supports the protective role of IgA in inflammatory processes.

The underlying mechanisms leading to IgA deficiency are multifarious and anomalies in lymphocytic apoptosis, cytokine networking, and costimulatory signaling, and the presence of predisposing MHC complex alleles has been described [44]. In A-T patients, it has been shown by Driessen et al. that antibody deficiency is the result of a disturbed $\mathrm{B}$ - and T-cell homeostasis and that naïve $\mathrm{CD} 4^{+} \mathrm{T}$-cell numbers are closely correlated with $\mathrm{CD}_{27} 7^{+} \mathrm{IgA}{ }^{+}$memory B-cells [14]. Phenotyping of our cohort of classical A-T patients revealed that patients with $\operatorname{Ig} \mathrm{A}$ deficiency had significantly lower lymphocyte counts compared to A-T patients without IgA deficiency due to a further decrease of naïve CD4 T-cells (CD4/CD45RA), whereas no differences in absolute B-cell numbers could be detected. T-cell imbalance was accompanied with lower central memory CD4 cells $\left(\mathrm{CD}^{+} 45 \mathrm{RO}^{+} 62 \mathrm{~L}^{+}\right.$cells) and regulatory T-cells. This is an interesting finding in regard of T-cell help to B-cells. Central memory (CM) T-cells home secondary lymphoid organs such as B-cell-enriched follicles and germinal centers to provide help to B-cells [45]. Some of these CM T-cells express CXCR5 and have been defined as T-follicular helper (Thf) cells. They induce B-cell differentiation and class-switching by ligation of CD40Ligand as well as T-cell-derived cytokines [46]. Another population of T-cells that augment the germinal center response are $\mathrm{T}$ follicular regulatory (Tfr) cells [47]. Tfr cells are a unique subset of Treg cells that are localized in the germinal center (GC) of the B-cell follicle. Thus, beside disturbed B-cell homeostasis, an incomplete T-cell help program could be responsible for reduced IgA levels in A-T patients with IgA deficiency. In addition, we compared the mutations of our patients with and without IgA deficiency. As shown in the supplement no distinctive patterns were identified. This is in line with previous reports and confirms that no correlation exists between ATM mutations and immunoglobulin phenotype [19, 48, 49].

In light of old and new emerging treatments, patients with classical A-T need to be better characterized on the immunoglobulin and molecular level. Immunoglobulin replacement and antibiotic prophylaxis could be helpful for patients with recurrent infections and bronchiectasis [50]. There is a phase 3 trial ongoing (Ataxia-Telangiectasia Trial with the EryDex SysTem) to evaluate the efficacy, safety, and tolerability of EryDex to prevent neurological decline in A-T (Erydel https:// www.erydel.com/News/April 14, 2020). Results of this large trial may be available in autumn 2021. Hematopoietic stem cell transplantation (HSCT) is an encouraging approach to correct immunity and prevent the development of hematologic malignancies [33]. However, to what extent the restored immune system and the increase of ATM protein may prevent neurological decline and the development of other malignancies is not known. In addition, the first patient is currently treated by an antisense oligonucleotide to block progression of neurodegeneration by injections in the spinal fluid. At present, the long-term outcome needs further evaluation.

Our study has several limitations; these include the fact that it was a retrospective analysis and not a prospective or randomized clinical trial. In addition, we analyzed two cohorts, the ESID data and the Frankfurt cohorts, which differ in several biological aspects. The distribution of IgA deficiency (ESID cohort (IgA-D 161/noDef 300) and Frankfurt (IgA-D 35/noDef 31) was statistically different $(p=0.009)$. The reasons for these differences are hardly to 
explain but may be due to a well-known bias of the ESID registry. Mainly pediatric immunologists who care for patients suffering from frequent infections and a more pronounced immunodeficiency collect the data of the ESID registry. Thus, more healthy patients are not entered in the registry. Nevertheless, to overcome these differences of the cohorts, we analyzed survival only in the ESID cohort and removed all Frankfurt data from this analysis. Vice versa, the ESID registry does neither provide data about lymphocyte subsets such as T- and B-cell numbers nor data about $\mathrm{T}$-cell rearrangement, these parameters were analyzed solely in the Frankfurt cohort. Although both cohorts differ in their ratio of IgA deficient and no deficient patients, the groups are well comparable in respect of the genetic background and the distribution of the other immunoglobulins and therefore well suited for the analyses performed. Moreover, as shown in the results section, the dataset of 659 registered A-T patients were rather incomplete. Only 461 patients had data available for IgA and only 171 patients for IgG subclasses. Maybe since IgG subclass analysis is a more sophisticated and expensive method than IgA measurement. The large imbalance of data might affect our Kaplan Meier curves of survival. Also, we must admit that the cause of the underlying mortality was rarely reported, and no corresponding mutations were known for patients in the registry.

IgA deficiency is difficult to diagnose in children $<4$ years according to international consensus [51]. However, the age range 5-61 years of the registered patients ruled out that the absence of IgA was simply related to the young age of patients. To further increase the specificity of our finding, we chose the criteria deficient IgA and partial IgA in comparison to normal IgA values. Finally, we cannot completely rule out that some "A-T variants" with residual ATM kinase activity may affect our finding sinceATM kinase activity was not measured in most A-T cases of the ESID registry. To overcome this drawback, we did a sensitivity analysis and excluded all patients who were not registered before the age of 9 years and who were older than 37.5 years to further minimize the presence of A-T variants, since A-T variants may develop symptoms much later than classical A-T cases [52]. The sensitivity analysis confirmed that A-T patients with absent IgA exhibit a lower survival rate than A-T patients without IgA deficiency.

In conclusion, for the first time our data show that patients with IgA deficiency have significantly lower lymphocyte counts and subsets, which is accompanied with reduced survival compared to patients without $\operatorname{Ig} \mathrm{A}$ deficiency. IgA, a simple surrogate marker, is indicating the poorest prognosis for classical A-T patients.

Supplementary Information The online version contains supplementary material available at https://doi.org/10.1007/s10875-021-01090-8 .
Acknowledgements The ESID Registry was in part used for collecting data for this study. It is based on contributions by the following national registries: CEREDIH (France), REDIP (Spain), PID-NET (Germany), UKPIN (UK), IPINET (Italy), AGPI (Austria), WID (the Netherlands), Greece, Russia, and Czech Republic. Additional contributions are received from the following countries: Turkey, Poland, Ireland, Iran, Lithuania, Portugal, Belgium, Switzerland, Slovakia, Slovenia, Sweden, Croatia, Serbia, Belarus, Hungary, Romania, Ukraine, Estonia, Egypt, and Israel.

Author Contribution All authors contributed to the management and documentation of patients, stud conception and design and gave their final approval to the submitted version. Stefan Zielen and Ralf Schubert performed data analysis and wrote the manuscript.

Funding Open Access funding enabled and organized by Projekt DEAL. The ESID Registry was supported by the German Federal Ministry of Education and Research (BMBF 01GM0896, 01GM1111B, 01GM1517C, 01EO1303 and 01ZZ1801B) EU grant no. HEALTHF2-2008-201549 (EURO-PADnet), the pharmaceutical companies Novartis, GlaxoSmithKline, LFB, and UCB UK, the Plasma Protein Therapeutics Association (PPTA), the Care-for-Rare Foundation, PROimmune e.V, LFB, and the Deutsche Forschungsgemeinschaft (DFG, German Research Foundation) under Germany's Excellence StrategyEXC 2155 RESIST-Project ID 39087428. EGD is supported by the UK National Institute of Health Research and the Great Ormond Street Hospital Biomedical Research Centre.

Data Availability The datasets for this manuscript are not publicly available due to the respective agreements with the documenting centers. Requests to access anonymized datasets should be directed to the ESID registry, e.g., via the corresponding author.

Code Availability Not applicable.

\section{Declarations}

Ethics Approval The study was conducted following the ethical principles of the Declaration of Helsinki, regulatory requirements, and the code of Good Clinical Practice. The study was approved by the responsible ethics committees in Frankfurt (Date May 22, 2012/No. 121/12, Date Nov 21, 2016, No. 504/15).

Consent to Participate Informed consent was obtained from all individual participants included in the study.

Consent for Publication Written informed consent for publication of their clinical details and was obtained from the patient/parent/guardian/relative of the patient. A copy of the consent form is available for review by the Editor of this journal.

Conflict of Interest The authors have the following conflicts to declare: Dr. Zielen reports honoraria from CSL-Behring, AstraZeneca; Sanofi-Aventis GmbH; Boehringer Ingelheim; Stallergenes Greer; Allergy Therapeutics, bene-Arzneimittel GmbH; Vifor Pharma GmbH; Novartis AG; GlaxoSmithKline GmbH; ALK-Abelló Arzneimittel $\mathrm{GmbH}$; Lofarma GmbH, IMS Health GmbH \& Co; and Biotest Pharma $\mathrm{GmbH}$, outside the submitted work.

Dr. Ehl reports grants from UCB, during the conduct of the study. Dr. Sabine M. El-Helou was funded by the Federal Ministry of Education and Research (BMBF), by the European Society for Immunodeficiencies (ESID), by the Care-for-Rare Foundation, by PROimmun 
e.V., and by a restricted grant from LFB, CSL Behring, and Grifols. For GAIN and RESIST, she was funded by the BMBF.

Dr. Kindle reports grants from ESID (European Society for Immunodeficiencies) and grants from BMBF (German Federal Ministry of Education and Research), during the conduct of the study.

Dr. van Aerde reports grants from Baxter, during the conduct of the study. Dr. Laws reports personal fees from Shire; Roche; Novonordisk; Pfizer; Csl Behring, outside the submitted work.

Dr. Niehues reports honoraria from uptodate.com; travelling costs from PENTA and JIR cohorts (Padua, Italy; Lausanne Switzerland), up to 2017 from PPTA (plasma protein therapeutics association).

Dr. Seidel reports personal fees from Shire [Hypogammaglobulinemia (Subcutaneous IgG, hyaluronic acid, immune globulin (human))], outside the submitted work.

Dr. Meyts reports grants from CSL Behring, outside the submitted work. IM is a senior clinical investigator at FWO Vlaanderen (supported by CSL Behring Chair of Primary Immunodeficiencies, by a KU Leuven C1 Grant C16/18/007, by a VIB GC PID Grant, by a FWO Grants G0C8517N; and G0E8420N and by the Jeffrey Modell Foundation. IM is a recipient of a ERC-StG MORE2ADA2. This work is supported by ERN-RITA.

Dr. Grimbacher reports grants from DZIF, DFG, BMBF, Fritz Thyssen Stiftung, Shire/Baxalta, Merck, BMS, Novartis, CSL Behring, personal fees from Janssen Cilag, Novartis, during the conduct of the study, outside the submitted work.

Dr. Schubert reports grants from A-T Children's Project, DFG, SPARKS-Action for A-T, Starke Lunge Foundation, personal fees from Biotest Pharma GmbH and Vifor Pharma Deutschland GmbH, outside the submitted work.

The other authors declare that the research was conducted in the absence of any commercial or financial relationships that could be construed as a potential conflict of interest.

Open Access This article is licensed under a Creative Commons Attribution 4.0 International License, which permits use, sharing, adaptation, distribution and reproduction in any medium or format, as long as you give appropriate credit to the original author(s) and the source, provide a link to the Creative Commons licence, and indicate if changes were made. The images or other third party material in this article are included in the article's Creative Commons licence, unless indicated otherwise in a credit line to the material. If material is not included in the article's Creative Commons licence and your intended use is not permitted by statutory regulation or exceeds the permitted use, you will need to obtain permission directly from the copyright holder. To view a copy of this licence, visit http://creativecommons.org/licenses/by/4.0/.

\section{References}

1. Boder E, Sedgwick RP. Ataxia-telangiectasia; a familial syndrome of progressive cerebellar ataxia, oculocutaneous telangiectasia and frequent pulmonary infection. Pediatrics. 1958;21:526-54.

2. Rothblum-Oviatt C, Wright J, Lefton-Greif MA, McGrath-Morrow SA, Crawford TO, Lederman HM. Ataxia telangiectasia: a review. Orphanet J Rare Dis. 2016;11:159. https://doi.org/10. 1186/s13023-016-0543-7.

3. Schroeder SA, Zielen S. Infections of the respiratory system in patients with ataxia-telangiectasia. Pediatr Pulmonol. 2014;49:389-99. https://doi.org/10.1002/ppul.22817.

4. Nissenkorn A, Levy-Shraga Y, Banet-Levi Y, Lahad A, Sarouk I, Modan-Moses D. Endocrine abnormalities in ataxia telangiectasia: findings from a national cohort. Pediatr Res. 2016;79:889-94. https://doi.org/10.1038/pr.2016.19.
5. Pommerening $\mathrm{H}$, van Dullemen $\mathrm{S}$, Kieslich M, Schubert R, Zielen S, Voss S. Body composition, muscle strength and hormonal status in patients with ataxia telangiectasia: a cohort study. Orphanet J Rare Dis. 2015;10:155. https://doi.org/10.1186/ s13023-015-0373-z.

6. Schubert R, Reichenbach J, Zielen S. Growth factor deficiency in patients with ataxia telangiectasia. Clin Exp Immunol. 2005;140:517-9. https://doi.org/10.1111/j.1365-2249.2005. 02782.x.

7. Voss S, Pietzner J, Hoche F, Taylor AMR, Last JI, Schubert R, Zielen S. Growth retardation and growth hormone deficiency in patients with Ataxia telangiectasia. Growth Factors. 2014;32:123 9. https://doi.org/10.3109/08977194.2014.939805.

8. Donath H, Woelke S, Theis M, Heß U, Knop V, Herrmann E, et al. Progressive liver disease in patients with ataxia telangiectasia. Front Pediatr. 2019;7:458. https://doi.org/10.3389/fped.2019. 00458.

9. Micol R, Ben Slama L, Suarez F, Le Mignot L, Beauté J, Mahlaoui $\mathrm{N}$, et al. Morbidity and mortality from ataxia-telangiectasia are associated with ATM genotype. J Allergy Clin Immunol. 2011;128:382-9.e1. https://doi.org/10.1016/j.jaci.2011.03.052.

10. Nowak-Wegrzyn A, Crawford TO, Winkelstein JA, Carson KA, Lederman HM. Immunodeficiency and infections in ataxia-telangiectasia. J Pediatr. 2004;144:505-11. https://doi.org/10.1016/j. jpeds.2003.12.046.

11. Schubert R, Reichenbach J, Zielen S. Deficiencies in CD4+ and $\mathrm{CD} 8+\mathrm{T}$ cell subsets in ataxia telangiectasia. Clin Exp Immunol. 2002;129:125-32. https://doi.org/10.1046/j.1365-2249.2002. 01830.x.

12. Reichenbach J, Schubert R, Feinberg J, Beck O, Rosewich M, Rose MA, Zielen S. Impaired interferon-gamma production in response to live bacteria and Toll-like receptor agonists in patients with ataxia telangiectasia. Clin Exp Immunol. 2006;146:381-9. https://doi.org/10.1111/j.1365-2249.2006.03221.x.

13. Schubert R, Reichenbach J, Rose M, Zielen S. Immunogenicity of the seven valent pneumococcal conjugate vaccine in patients with ataxia-telangiectasia. Pediatr Infect Dis J. 2004;23:269-70.

14. Driessen GJ, Ijspeert H, Weemaes CMR, Haraldsson Á, Trip M, Warris A, et al. Antibody deficiency in patients with ataxia telangiectasia is caused by disturbed B- and T-cell homeostasis and reduced immune repertoire diversity. J Allergy Clin Immunol. 2013;131:1367-75.e9. https://doi.org/10.1016/j.jaci.2013.01.053.

15. Giovannetti A, Mazzetta F, Caprini E, Aiuti A, Marziali M, Pierdominici M, et al. Skewed T-cell receptor repertoire, decreased thymic output, and predominance of terminally differentiated T cells in ataxia telangiectasia. Blood. 2002;100:4082-9. https://doi.org/10.1182/blood-2002-03-0976.

16. Bagley J, Singh G, Iacomini J. Regulation of oxidative stress responses by ataxia-telangiectasia mutated is required for $\mathrm{T}$ cell proliferation. J Immunol. 2007;178:4757-63. https://doi.org/10. 4049/jimmunol.178.8.4757.

17. Matei IR, Gladdy RA, Nutter LMJ, Canty A, Guidos CJ, Danska JS. ATM deficiency disrupts Tcra locus integrity and the maturation of CD4+CD8+ thymocytes. Blood. 2007;109:1887-96. https://doi.org/10.1182/blood-2006-05-020917.

18. Carney EF, Srinivasan V, Moss PA, Taylor AM. Classical ataxia telangiectasia patients have a congenitally aged immune system with high expression of CD95. J Immunol. 2012;189:261-8. https://doi.org/10.4049/jimmunol.1101909.

19. van Os NJH, Jansen AFM, van Deuren M, Haraldsson A, van Driel NTM, Etzioni A, et al. Ataxia-telangiectasia: immunodeficiency and survival. Clin Immunol. 2017;178:45-55. https://doi. org/10.1016/j.clim.2017.01.009.

20. Verhagen MMM, Last JI, Hogervorst FBL, Smeets DFCM, Roeleveld N, Verheijen F, et al. Presence of ATM protein and residual kinase activity correlates with the phenotype in 
ataxia-telangiectasia: a genotype-phenotype study. Hum Mutat. 2012;33:561-71. https://doi.org/10.1002/humu.22016.

21. Ambrose M, Gatti RA. Pathogenesis of ataxia-telangiectasia: The next generation of ATM functions. Blood. 2013;121:4036-45. https://doi.org/10.1182/blood-2012-09-456897.

22. Barlow C, Dennery PA, Shigenaga MK, Smith MA, Morrow JD, Roberts LJ, et al. Loss of the ataxia-telangiectasia gene product causes oxidative damage in target organs. Proc Natl Acad Sci U S A. 1999;96:9915-9. https://doi.org/10.1073/pnas.96.17.9915.

23. Ito K, Hirao A, Arai F, Matsuoka S, Takubo K, Hamaguchi I, et al. Regulation of oxidative stress by ATM is required for self-renewal of haematopoietic stem cells. Nature. 2004;431:997-1002. https:// doi.org/10.1038/nature02989.

24. Reichenbach J, Schubert R, Schindler D, Müller K, Böhles H, Zielen S. Elevated oxidative stress in patients with ataxia telangiectasia. Antioxid Redox Signal. 2002;4:465-9. https://doi.org/ 10.1089/15230860260196254.

25. Barlow C, Eckhaus MA, Schäffer AA, Wynshaw-Boris A. Atm haploinsufficiency results in increased sensitivity to sublethal doses of ionizing radiation in mice. Nat Genet. 1999;21:359-60. https://doi.org/10.1038/7684.

26. Woelke S, Valesky E, Bakhtiar S, Pommerening H, Pfeffermann LM, Schubert R, Zielen S. Treatment of granulomas in patients with ataxia telangiectasia. Front Immunol. 2018;9:2000. https:// doi.org/10.3389/fimmu.2018.02000.

27. Krauthammer A, Lahad A, Goldberg L, Sarouk I, Weiss B, Somech R, et al. Elevated IgM levels as a marker for a unique phenotype in patients with Ataxia telangiectasia. BMC Pediatr. 2018;18:185. https://doi.org/10.1186/s12887-018-1156-1.

28. Mohammadinejad P, Abolhassani H, Aghamohammadi A, Pourhamdi S, Ghosh S, Sadeghi B, et al. Class switch recombination process in ataxia telangiectasia patients with elevated serum levels of IgM. J Immunoassay Immunochem. 2015;36:16-26. https://doi. org/10.1080/15321819.2014.891525.

29. Folgori L, Scarselli A, Angelino G, Ferrari F, Antoccia A, Chessa L, Finocchi A. Cutaneous granulomatosis and combined immunodeficiency revealing Ataxia-Telangiectasia: A case report. Ital J Pediatr. 2010;36:29. https://doi.org/10.1186/1824-7288-36-29.

30. van Os NJH, Chessa L, Weemaes CMR, van Deuren M, Fiévet A, van Gaalen J, et al. Genotype-phenotype correlations in ataxia telangiectasia patients with ATM c.3576GA and c.8147TC mutations. J Med Genet. 2019;56:308-16. https://doi.org/10.1136/ jmedgenet-2018-105635.

31. Ludvigsson JF, Neovius M, Hammarström L. Risk of Infections Among 2100 Individuals with IgA deficiency: a nationwide cohort study. J Clin Immunol. 2016;36:134-40. https://doi.org/10.1007/ s10875-015-0230-9.

32. Weber-Mzell D, Kotanko P, Hauer AC, Goriup U, Haas J, Lanner N, et al. Gender, age and seasonal effects on IgA deficiency: a study of 7293 Caucasians. Eur J Clin Invest. 2004;34:224-8. https://doi.org/10.1111/j.1365-2362.2004.01311.x.

33. Bakhtiar $\mathrm{S}$, Woelke $\mathrm{S}$, Huenecke $\mathrm{S}$, Kieslich M, Taylor AM, Schubert R, et al. Pre-emptive allogeneic hematopoietic stem cell transplantation in ataxia telangiectasia. Front Immunol. 2018;9:2495. https://doi.org/10.3389/fimmu.2018.02495.

34 Shannon CE. The mathematical theory of communication. 1963. MD Comput. 1997;14:306-17.

35. O'Connell AE, Volpi S, Dobbs K, Fiorini C, Tsitsikov E, de Boer $\mathrm{H}$, et al. Next generation sequencing reveals skewing of the $\mathrm{T}$ and $\mathrm{B}$ cell receptor repertoires in patients with wiskott-Aldrich syndrome. Front Immunol. 2014;5:340. https://doi.org/10.3389/ fimmu.2014.00340.

36. Leuzzi V, Micheli R, D’Agnano D, Molinaro A, Venturi T, Plebani A, et al. Positive effect of erythrocyte-delivered dexamethasone in ataxia-telangiectasia. Neurol Neuroimmunol Neuroinflamm. 2015;2: e98. https://doi.org/10.1212/NXI.0000000000000098.
37. Zielen S, Schubert R. Workshop report: European workshop on ataxia-telangiectasia, Frankfurt, 2011. J Neurogenet. 2011;25:7881. https://doi.org/10.3109/01677063.2011.592553.

38. Sanal O, Ersoy F, Yel L, Tezcan I, Metin A, Ozyürek H, et al. Impaired IgG antibody production to pneumococcal polysaccharides in patients with ataxia-telangiectasia. J Clin Immunol. 1999;19:326-34. https://doi.org/10.1023/a:1020599810261.

39. Panchakshari RA, Zhang X, Kumar V, Du Z, Wei P-C, Kao J, et al. DNA double-strand break response factors influence end-joining features of $\mathrm{IgH}$ class switch and general translocation junctions. Proc Natl Acad Sci U S A. 2018;115:762-7. https://doi.org/10. 1073/pnas.1719988115.

40. Amirifar P, Mozdarani H, Yazdani R, Kiaei F, Moeini Shad T, Shahkarami S, et al. Effect of class switch recombination defect on the phenotype of ataxia-telangiectasia Patients. Immunol Invest. 2020:1-15. https://doi.org/10.1080/08820139.2020.1723104 .

41. Yazdani R, Latif A, Tabassomi F, Abolhassani H, Azizi G, Rezaei $\mathrm{N}$, Aghamohammadi A. Clinical phenotype classification for selective immunoglobulin A deficiency. Expert Rev Clin Immunol. 2015;11:1245-54. https://doi.org/10.1586/1744666X.2015. 1081565.

42. Breedveld A, van Egmond M. IgA and FcoRI: pathological roles and therapeutic opportunities. Front Immunol. 2019;10:553. https://doi.org/10.3389/fimmu.2019.00553.

43. Pasquier B, Launay P, Kanamaru Y, Moura IC, Pfirsch S, Ruffié $\mathrm{C}$, et al. Identification of FcalphaRI as an inhibitory receptor that controls inflammation: Dual role of FcRgamma ITAM. Immunity. 2005;22:31-42. https://doi.org/10.1016/j.immuni.2004.11.017.

44. Bagheri Y, Sanaei R, Yazdani R, Shekarabi M, Falak R, Mohammadi J, et al. The Heterogeneous pathogenesis of selective immunoglobulin a deficiency. Int Arch Allergy Immunol. 2019;179:231-46. https://doi.org/10.1159/000499044.

45. Sallusto F, Geginat J, Lanzavecchia A. Central memory and effector memory T cell subsets: Function, generation, and maintenance. Annu Rev Immunol. 2004;22:745-63. https://doi.org/10.1146/ annurev.immunol.22.012703.104702.

46. Ramiscal RR, Vinuesa CG. T-cell subsets in the germinal center. Immunol Rev. 2013;252:146-55. https://doi.org/10.1111/imr. 12031.

47. Amiezer M, Phan TG. Disentangling Tfr cells from Treg cells and Tfh cells: how to untie the Gordian knot. Eur J Immunol. 2016;46:1101-4. https://doi.org/10.1002/eji.201646389.

48. Morio T, Takahashi N, Watanabe F, Honda F, Sato M, Takagi $\mathrm{M}$, et al. Phenotypic variations between affected siblings with ataxia-telangiectasia: ataxia-telangiectasia in Japan. Int J Hematol. 2009;90:455-62. https://doi.org/10.1007/s12185-009-0408-0.

49. Soresina A, Meini A, Lougaris V, Cattaneo G, Pellegrino S, Piane $\mathrm{M}$, et al. Different clinical and immunological presentation of ataxia-telangiectasia within the same family. Neuropediatrics. 2008;39:43-5. https://doi.org/10.1055/s-2008-1076736.

50. Bhatt JM, Bush A, van Gerven M, Nissenkorn A, Renke M, Yarlett $\mathrm{L}$, et al. ERS statement on the multidisciplinary respiratory management of ataxia telangiectasia. Eur Respir Rev. 2015;24:565-81. https://doi.org/10.1183/16000617.0066-2015.

51. Notarangelo LD, Fischer A, Geha RS, Casanova J-L, Chapel H, Conley ME, et al. Primary immunodeficiencies: 2009 update. J Allergy Clin Immunol. 2009;124:1161-78. https://doi.org/10. 1016/j.jaci.2009.10.013.

52. Schon K, van Os NJH, Oscroft N, Baxendale H, Scoffings D, Ray $\mathrm{J}$, et al. Genotype, extrapyramidal features, and severity of variant ataxia-telangiectasia. Ann Neurol. 2019;85:170-80. https://doi. org/10.1002/ana.25394.

Publisher's Note Springer Nature remains neutral with regard to jurisdictional claims in published maps and institutional affiliations. 


\section{Authors and Affiliations}

Stefan Zielen ${ }^{1} \cdot$ Ruth Pia Duecker $^{1} \cdot$ Sandra Woelke $^{1} \cdot$ Helena Donath $^{1} \cdot$ Sharhzad Bakhtiar $^{2} \cdot$ Aileen Buecker $^{1}$. Hermann Kreyenberg ${ }^{2}$. Sabine Huenecke ${ }^{2}$. Peter Bader ${ }^{2}$ - Nizar Mahlaoui ${ }^{3}$. Stephan Ehl ${ }^{4}$. Sabine M. El-Helou ${ }^{4,5,6}$. Barbara Pietrucha ${ }^{7}$. Alessandro Plebani ${ }^{8} \cdot$ Michiel van der Flier ${ }^{9} \cdot$ Koen van Aerde ${ }^{10} \cdot$ Sara S. Kilic $^{11}$. Shereen M. Reda ${ }^{12}$. Larysa Kostyuchenko ${ }^{13}$. Elizabeth McDermott ${ }^{14} \cdot$ Nermeen Galal $^{15}$. Claudio Pignata ${ }^{16}$. Juan Luis Santos Pérez ${ }^{17} \cdot$ Hans-Juergen Laws ${ }^{18} \cdot \operatorname{Tim}_{\text {Niehues }}{ }^{19} \cdot$ Necil Kutukculer $^{20} \cdot$ Markus G. Seidel $^{21}$. Laura Marques $^{22}$. Peter Ciznar ${ }^{23}$. John David M. Edgar ${ }^{24}$. Pere Soler-Palacín ${ }^{25}$ • Horst von Bernuth ${ }^{26,27,28}$. Renate Krueger ${ }^{26}$. Isabelle Meyts ${ }^{29}$. Ulrich Baumann ${ }^{30}$. Maria Kanariou ${ }^{31}$ • Bodo Grimbacher ${ }^{4,5,32} \cdot$ Fabian Hauck $^{33}$. Dagmar Graf $^{34}$ • Luis Ignacio Gonzalez Granado ${ }^{35}$. Seraina Prader ${ }^{36}$. Ismail Reisli L $^{37}$. Mary Slatter ${ }^{38}$. Carlos Rodríguez-Gallego ${ }^{39}$. Peter D. Arkwright ${ }^{40}$. Claire Bethune ${ }^{41}$. Elena Deripapa ${ }^{42} \cdot$ Svetlana O. Sharapova $^{43}$. Kai Lehmberg ${ }^{44}$. E. Graham Davies ${ }^{45}$. Catharina Schuetz ${ }^{46} \cdot$ Gerhard Kindle $^{4,47} \cdot$ Ralf Schubert $^{1}$

1 Division of Allergology, Pulmonology and Cystic Fibrosis, Department for Children and Adolescents, Goethe University, Frankfurt, Germany

2 Division for Stem Cell Transplantation, Immunology and Intensive Care Unit, Department for Children and Adolescents, Goethe University, Frankfurt, Germany

3 Pediatric Immunology-Hematology and Rheumatology Unit, French National Reference Center for Primary Immune Deficiencies (CEREDIH), Necker Children's University Hospital, Assistance Publique-Hôpitaux de Paris (AP-HP), Paris, France

4 Institute for Immunodeficiency, Center for Chronic Immunodeficiency (CCI), Medical Center - University of Freiburg, Faculty of Medicine, University of Freiburg, Freiburg, Germany

5 RESIST - Cluster of Excellence 2155 To Hanover Medical School, Satellite Center Freiburg, Freiburg, Germany

6 Department of Rheumatology and Immunology, Hannover Medical School, Hannover, Germany

7 Department of Immunology, The Children's Memorial Health Institute, Av. Dzieci Polskich 20, 04-730 Warsaw, Poland

8 Pediatrics Clinic and Institute for Molecular Medicine A. Nocivelli, Department of Clinical and Experimental Sciences, University of Brescia and ASST-Spedali Civili di Brescia, Brescia, Italy

9 Section Pediatric Infectious Diseases, Laboratory of Medical Immunology, Radboud Institute for Molecular Life Sciences, Radboud University Medical Center, Nijmegen, the Netherlands

10 Department of Pediatrics, Amalia's Children Hospital, Radboud University Medical Center, Nijmegen, the Netherlands

11 Department of Pediatric Immunology and Rheumatology, the School of Medicine, Uludag University, Bursa, Turkey

12 Department of Pediatrics, Children's Hospital, Faculty of Medicine, Ain Shams University, Cairo, Egypt

13 Center of Pediatric Immunology, Western Ukrainian Specialized Children's Medical Centre, Lviv, Ukraine

14 Clinical Immunology and Allergy Unit, Nottingham University Hospitals, Nottingham, UK
15 Department of Pediatrics, Cairo University Specialized Pediatric Hospital, Cairo, Egypt

16 Department of Translational Medical Sciences, Section of Pediatrics, Federico II University, Naples, Italy

17 Infectious Diseases and Immunodeficiencies Unit, Service of Pediatrics, Hospital Universitario Virgen de Las Nieves, Granada, Spain

18 Department of Pediatric Oncology, Hematology and Clinical Immunology, Medical Faculty, Center of Child and Adolescent Health, Heinrich-Heine University, Duesseldorf, Germany

19 Centre for Child and Adolescent Health, Helios Klinikum Krefeld, Krefeld, Germany

20 Faculty of Medicine, Department of Pediatric Immunology, Ege University, Izmir, Turkey

21 Research Unit for Pediatric Hematology and Immunology, Division of Pediatric Hemato-Oncology, Department of Pediatrics and Adolescent Medicine, Medical University Graz, Graz, Austria

22 Pediatric Department, Infectious Diseases and Immunodeficiencies Unit, Porto Hospital Center, Porto, Portugal

23 Pediatric Department, Faculty of Medicine, Children University Hospital in Bratislava, Comenius University in Bratislava, Bratislava, Slovakia

24 The Royal Hospitals \& Queen's University, Belfast, UK

25 Pediatric Infectious Diseases and Immunodeficiencies Unit, Vall D'Hebron Research Institute, Hospital Universitari Vall D'Hebron, Universitat Autònoma de Barcelona, Barcelona, Catalonia, Spain

26 Department of Pediatric Pneumology, Immunology and Intensive Care, Charité - Universitätsmedizin Berlin, Berlin, Germany

27 Department of Immunology, Labor Berlin Charité - Vivantes $\mathrm{GmbH}$, Berlin, Germany

28 Berlin Center for Regenerative Therapies (BCRT), Charité Universitätsmedizin Berlin, Berlin, Germany

29 Department of Pediatrics, University Hospitals Leuven, and the Laboratory for Inborn Errors of Immunity, Department of Microbiology, Immunology and Transplantation, KU Leuven, Leuven, Belgium 
30 Department of Paediatric Pulmonology, Allergy and Neonatology, Hannover Medical School, Hannover, Germany

31 Department of Immunology and Histocompatibility, Centre for Primary Immunodeficiencies, "Aghia Sophia” Children's Hospital, Athens, Greece

32 DZIF-German Center for Infection Research, Satellite Center Freiburg, Freiburg, Germany; Centre for Integrative Biological Signalling Studies, Albert-Ludwigs University, Freiburg, Germany

33 Department of Pediatrics, Dr. Von Hauner Children's Hospital, University Hospital, Ludwig-Maximilians-University Munich, Munich, Germany

34 MVZ Dr. Reising-Ackermann Und Kollegen, Leipzig, Germany

35 Primary Immunodeficiencies Unit, Pediatrics, Hospital 12 Octubre, Complutense University School of Medicine, Madrid, Spain

36 Division of Immunology and Children's Research Center, University Children's Hospital Zurich, Zurich, Switzerland Department of Pediatrics, Division of Pediatric Immunology and Allergy, Meram Medical Faculty, Necmettin Erbakan University, Konya, Turkey

38 Primary Immunodeficiency Group, Paediatric Immunology and Haematopoietic Stem Cell Transplantation, Translational and Clinical Research Institute, Great North Childrens' Hospital, Newcastle University, Newcastle upon Tyne, UK

39

Department of Immunology, Dr. Negrin University Hospital of Gran Canaria, University Fernando Pessoa Canarias, Las Palmas de Gran Canaria, Spain

40 Lydia Becker Institute of Immunology and Inflammation, University of Manchester and Royal Manchester Children's Hospital, Manchester, UK

41 University Hospital Plymouth NHS Trust, Plymouth, UK

42 National Medical Research Center of Pediatric Hematology, Oncology and Immunology, Moscow, Russia

43 Research Department, Belarusian Research Center for Pediatric Oncology, Hematology and Immunology, Minsk region, Minsk, Belarus

44 Division for Pediatric Stem Cell Transplantation and Immunology, Clinic for Pediatric Hematology and Oncology, University Medical Center Hamburg-Eppendorf, Hamburg, Germany

45 Great Ormond Street Hospital and UCL Great Ormond Street Institute of Child Health, London, UK

46 Department of Pediatrics, Medizinische Fakultät Carl Gustav Carus, Technische Universität Dresden, Dresden, Germany

47 FREEZE Biobank, Center for Biobanking, Medical Center and Faculty of Medicine, University of Freiburg, Breisacher Str. 115, 79106 Freiburg, Germany 